ojs.uv.es/index.php/qfilologia/index

Rebut: i6.06.2020. Acceptat: 08.07.2020

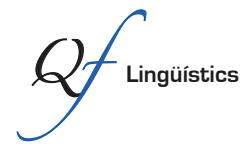

Per a citar aquest article: García Martín, Ana María. 2020. “Três teorias sobre a origem da língua portuguesa”. Quaderns de Filologia: Estudis Lingüístics XXV: I5-28.

doi: $10.7203 /$ QF.25.19065

\title{
Três teorias sobre a origem da língua portuguesa
}

Three theories on the origin of the Portuguese Language

\author{
Ana María García Martín \\ Universidad de Salamanca \\ amgm@usal.es
}

Resumo: Expõem-se as principais teorias sobre a origem da língua portuguesa presentes em destacados textos metalinguísticos portugueses escritos entre os séculos xvi e xix. Pretende-se mostrar como as três teorias analisadas se integram no contexto de pensamento linguístico coevo, assim como a sua ligação com os discursos fundacionais da nação.

Palavras-chave: historiografia linguística; origem; português.

Abstract: The main theories on the origin of the Portuguese language are presented in outstanding Portuguese metalinguistic texts written between the I6th and Igth centuries. The aim is to show how the three theories analyzed are integrated in a context of contemporary linguistic thought and its link with the nation's foundational discourses.

Keywords: Linguistic Historiography; Origin; Portuguese.

\section{Introdução}

Os discursos sobre a origem das línguas vernáculas europeias intensificaram-se em momentos históricos que podemos relacionar com a construção de um sentimento de identidade nacional. A progressiva modelação dos estados-nação na Europa favoreceu a busca de uma identidade própria comummente alicerçada na possessão de uma língua comum como elemento aglutinador. As teorias sobre a origem das línguas assumem, nesses contextos, grande valor. Pretendemos aqui interpretar as teorias sobre a origem da língua portuguesa que tiveram maior curso em dois momentos salientes de construção da identidade nacional, os séculos xvi e xIx, em que se experimentou um impulso da 
gramatização e da reflexão sobre os vernáculos ${ }^{\mathrm{I}}$. Respondendo às correntes culturais próprias de cada um desses momentos históricos, as diferentes teorias sobre a origem da língua portuguesa tratadas vinculam-se à construção de uma identidade nacional, de forma que a busca das origens linguísticas é em grande parte a busca da matriz da identidade própria.

\section{A teoria da corruptio linguae e a limitação do português primitivo}

Desde os inícios da reflexão sobre os vernáculos, no âmbito românico, prevaleceu com clareza a ideia de que as línguas românicas se filiavam diretamente no latim, de que eram filhas, descendentes diretas, da língua latina. Esta filiação é, também, o mais importante argumento de louvor das línguas nesse momento, que disputam entre si qual delas seja a mais parecida ao latim. Assim, o português é defendido pelos autores portugueses como a língua mais próxima do latim, e portanto a menos deturpada ou "corrupta", entre as congéneres românicas, em relação à língua mãe. Contudo, a teoria da corruptio linguae, comum ao humanismo renascentista, faz com que os romanços sejam considerados como sistemas muito deficitários em comparação com a perfeição e riqueza da língua que lhes deu origem. Se os humanistas constatavam evidências no léxico e nas estruturas gramaticais compartilhadas que lhes permitiam afirmar sem dúvida a filiação latina, também não podiam deixar de reconhecer as divergências, de maior ou menor vulto, que as afastavam da língua mãe. A perceção de que os romances são línguas limitadas, pobres expressiva e gramaticalmente, muito inferiores ao latim, é ainda geral no âmbito do Renascimento românico. Ora, essa menoridade linguística será explicada como resultado de um processo de corrupção da língua mãe, derivado da mistura do povo latino com outros povos invasores do espaço românico no final do império. Assim, o cruzamento linguístico explicaria o nascimento das novas línguas romances, cuja admitida origem mista é considerada como uma mácula original, um certificado de bastardia, enquanto que a língua latina se mantinha incólume como privilegiado instrumento de expressão em

\footnotetext{
I Também no século xix se produz uma expansão funcional dos vernáculos escritos, devido a que a burocracia cresce em toda a Europa, convertendo a literacia numa necessidade para massas sociais que procuram uma promoção de classe agora possível. B. Anderson (I99I: 67) assinala a importância ideológica e política dos national print-languages na Europa oitocentista, e considera que nesse continente os nacionalismos do período se construíram sobre modelos proporcionados por antecessores.
} 
sua riqueza gramatical e lexical. É por isso que parte do trabalho dos gramáticos do momento será perfilar e restaurar a identidade linguística herdeira do paradigma latino ${ }^{2}$. Ao afirmar uma identidade linguística comum, a românica, inserida num panorama cultural herdeiro da latinitas, coloca-se em destaque uma origem nobilitadora que exorciza o complexo da origem modesta dos vulgares.

Efetivamente, a denominada teoria da catástrofe (Marazzini, 1999: 29) é assumida pela maior parte dos humanistas da România, prevalecendo com clareza no Renascimento hispânico. Fica ainda longe um conceito parecido ao que hoje denominamos latim vulgar, de um latim não literário, falado, que pudesse supor a base genética das línguas romances. Todavia, esta ideia, embora demorasse a tomar corpo, desponta já no próprio Renascimento. O precedente mais conhecido é o do italiano Leonardo Bruni, que na Florença do século xv tinha mantido que o latim clássico não fora na realidade usado pelo povo de Roma, mas apenas pela classe mais culta, discutindo a homogeneidade secular da língua latina. Esta teoria, no entanto, passara quase despercebida no seu momento, prevalecendo, também na Itália, a hipótese que considerava os vulgares românicos como línguas mistas (cf. Marazzini, I999: 27-32).

Nebrija pode ser considerado como o primeiro representante da teoria da catástrofe, pois embora considere que a língua latina começara a deturpar-se na época imperial, teria contribuído fortemente para a sua alteração a mistura do povo hispano com o povo godo3. Décadas depois, Valdés introduz no seu conhecido Diálogo de la lengua um novo elemento responsável pela deturpação do latim, o substrato pré-romano (concretamente da língua grega), referindo também como decisiva a influência árabe ${ }^{4}$. Valdés também assume, portanto, uma origem mista, embora com menor responsabilidade dos

\footnotetext{
${ }^{2}$ É também verdade que os tratados renascentistas mostram uma constante ambiguidade na relação entre romance e latim, pois se o latim é um constante modelo para a codificação gramatical também não falta nos discursos gramaticais a afirmação dos traços distintivos e peculiares do romance.

3 "cuando la ocuparon los godos. los cuales no sola mente acabaron de corromper el latin i lengua romana: que ia con las muchas guerras avia començado a desfallecer: mas aun torcieron las figuras i traços de las letras antíguas" (Nebrija, [I492] I992: II9).

4 "la lengua que oy se habla en Castilla, de la qual vosotros queréis ser informados, tiene parte de la lengua que se usava en España antes que los romanos la enseñoreassen, y tiene también alguna parte de la de los godos, que sucedieron a los romanos, y mucha de la de los moros, que reinaron muchos años, aunque la principal parte es de la lengua que introduxeron los romanos, que es la lengua latina" (Valdés, [1535] I985: 53).
} 
povos germânicos na deturpação do latims. Interessa também referir que o humanista refuta que o basco pudesse ter constituído a língua peninsular pré-romana ao tempo da conquista, opinião que contava com adeptos já nesse momento, defendendo Valdés esse estatuto original para o grego (cf. Valdés, [1535] I985: 52-54). Enraizando-o na genealogia do castelhano, o grego, uma das três línguas clássicas a que Barros denomina "princesas do mundo", nobilita a matriz castelhana, como o próprio Barros fará com o hebraico.

Mas é a obra de Bernardo Aldrete, Del origen y principio de la lengua casteIlana ò romance que oi se usa en España, publicada em I606, o mais significativo expoente da teoria da catástrofe no âmbito hispânico. Com o propósito explícito de discutir teses que já circulavam nesse momento negando a filiação latina do romance castelhano e remontando-o diretamente a Babel (a denominada teoria do castelhano primitivo, cf. Binotti I995), Aldrete enfatiza a responsabilidade dos povos germânicos na deturpação do latim, embora também se mostre ciente da possível atuação de fatores internos à própria língua, aos quais concede, no entanto, menor importância. Aldrete defende abertamente que os godos não souberam assimilar as estruturas complexas da língua latina, corrompendo-a, adotando logo o povo hispânico submetido os hábitos linguísticos dos seus senhores:

i siendoles prolixa la declinacion de los nombres Latinos, i la variacion de los verbos por sus tiempos, contentaronse con vsar de los nombres Latinos, i dexaron la declinacion, la qual tomaron de su lengua. En la qual los nombres son indeclinables, i los casos se distinguen por los articulos, i preposiciones, como oi se vsa en la lengua italiana, i Española (Aldrete, [1606] I975: I53)

Aldrete não coloca, pois, a possibilidade de existência de um latim de dupla face, culto e vulgar, postulando a unidade básica do latim imperial. Ora, estas ideias prevalentes no contexto hispânico são reproduzidas em Portugal na Origem da língua portuguesa de Duarte Nunes do Leão, obra que pode ser considerada como principal expoente da teoria da catástrofe nesse país, e justamente editada no mesmo ano que a obra de Aldrete, i6o6. Nunes do Leão afirma que a língua latina que se falava na Hispânia romana era

\footnotetext{
5 "la lengua latina [...] assí mezclada y algo corrompida, se platicó en España hasta la venida de los godos, los quales, aunque no desterraron la lengua latina, todavía la corrompieron con la suya, de manera que ya la lengua latina tenía en España dos mezclas, una de la griega, según mi opinión, y otra de los godos" (Valdés, [I535] I985: 57) .
} 
pura, como em Roma, e no mesmo Lácio, até à vinda dos Vândalos, Alanos, Godos e Suevos e outros bárbaros que aos Romanos sucederam e corromperam a língua latina com a sua e a misturaram de muitos vocábulos, assim seus como de outras nações bárbaras que consigo trouxeram, de que se veio fazer a língua, que tem fundamentos da Romana, ainda que, corrupta lhe chamamos hoje romance. (Leão, [1606] I983: 2I7)

O autor português insiste na pureza do latim falado na Hispânia ("ficou a língua latina comum a todos, como se falava em Roma"), como demonstraria a quantidade de homens de letras ilustres que a Hispânia deu (Leão, [I606] I983: 218), tendo sido a chegada posterior e mistura de povos o que teria provocado a fratura desse latim puro. $\mathrm{O}$ autor português descreve dois passos nesse processo, o primeiro provocado pela chegada dos povos germânicos, que "com sua bárbara língua corromperam a latina e a misturaram com a sua" (Leão, [1606] I983: 219); e a posterior invasão árabe: "Depois desta barbária que se introduziu, veio a perdição de toda Espanha, que os Mouros assolaram e destruíram" (ibidem), de modo que: "vivendo entre eles, corromperam ainda mais a língua, meia gótica e meia latina que falavam, tomando outros vocábulos dos Mouros, que ainda hoje nos duram." (ibidem). Dessa língua latina já adulterada proviria a cisão em diferentes línguas romances: "ficou aquela língua gótica, que era comum a toda Espanha, fazendo algũa divisão e mudança entre si cada um em sua região, segundo era a gente com que tratavam" (ibidem). A deturpação da língua latina que está na origem das línguas romances é explicada em Nunes do Leão, portanto, como em Aldrete, como o resultado do contacto linguístico, enfatizando o carácter deturpador dos povos espúrios invasores da Hispânia.

Reconhecer as línguas como objetos históricos e assumir a capacidade de ação do tempo sobre elas significava, todavia, que a sua mutabilidade as tornava objetos suscetíveis de cultivo e aperfeiçoamento através da intervenção humana. Apenas um desenvolvimento concebido como progresso permitiria a superação do estado de limitação original dos romanços. A reivindicação desta ideia de progresso, através da aplicação da metáfora biológica à língua castelhana, faz Nebrija afirmar que o castelhano, tendo superado a sua menoridade original, se encontra no seu momento de plenitude no reinado dos Reis Católicos (Nebrija, [1492] I992: I03). Essa ideia de evolução compensa, portanto, a de corrupção original, mostrando que as línguas podem transcender a sua origem bastarda. Ora, esse mesmo argumento será muito frequente nos humanistas portugueses. Paira sobre todo o Diálogo em louvor da nossa linguagem a assunção da pobreza lexical do português, considerada em 
comparação com as outras línguas românicas, e mais concretamente com o castelhano. À pergunta explícita realizada pela personagem do Filho a respeito disso ${ }^{6}$, a personagem do Pai (trasunto do próprio Barros) apenas responderá, depois de ter encarecido a "conformidade com a latina" (Barros, [I540] I97I: 397) da língua portuguesa e as suas capacidades expressivas "pera declarár, mover, deleitár e exortár a párte a que se enclina” (Barros, [I540] I97I: 40o), defendendo o uso do empréstimo lexical ao latim como mecanismo idóneo para enriquecer o léxico português. Porque "Este exerçíçio, se ô nós usáramos, já tivéramos conquistáda a língua latina" (Barros, [I540] I97I: 40I). O tempo como fator deturpador, que "trouxe a barbária dos godos" e "nos deu xa e cha dos mouriscos" (Barros, [I540] I97I: 403), servirá agora para o enriquecimento do português, pois "O tempo [...] fáz as cousas tam naturáes, como a própria natureza” (ibidem).

Também em Leão há assunção da precariedade original do português: "Era a língua portuguesa, na saída daquele cativeiro dos Mouros, mui rude e mui curta e falta de palavras e cousas, por o mísero estado em que a terra estivera, o que lhe conveio tomar de outras gentes, como fez." (Leão, [1606] I983: 220). Mas, como Nebrija, o autor português irá servir-se da metáfora biológica para exemplificar o amadurecimento do português: "Pelo que sua meninice foi no tempo de el-rei D. Afonso VI de Castela e do Conde D. Henrique, até o de el-rei D. Dinis de Portugal, que teve algũa polícia e foi o primeiro que pôs as leis em ordem e mandou fazer compilação delas e compôs muitas cousas à imitação dos poetas proençais..." (ibidem). Esse melhoramento da língua é, para o autor, paralelo ao realizado para o castelhano, de maneira que "assim se foram ornando ambas as línguas, portuguesa e castelhana, até à polícia em que agora estão" (ibidem). O enriquecimento através do tratamento literário e da tradução permitirá superar a assumida ideia da limitação original do português, como se comprova no Diálogo em louvor de Barros e no Diálogo em defensão de Magalhães de Gândavo7. Por sua parte, a defesa da filiação da

\footnotetext{
6 "Pois muitos dizem que a língua espanhól é desfaleçida de vocábulos, e que, quanta vantáge tem a italiana à castelhana, tanto exçéde ésta a portuguesa, e que em seu respeito se póde chamár elegante." (Barros, [I540] I97I: 397).

$7 \mathrm{O}$ argumento da limitação linguística das origens é usado pela personagem Falêncio logo no início do diálogo: "La causa señor Petronio, de vuestra lengua ser juzgada por essa [a mais grosseira do mundo] (no solo de todas las naciones del mundo, mas aun de los mismos portugueses que la posseen) es porque en su principio como se puede ver en el lenguaje de algunas historias y chronicas antiguas de Portugal, vsauan muchos vocabulos muy differentes y improprios de su natural significacion y origen." (Gândavo, [I574] I98I: 44-45). O argumento será contestado pela personagem Petrónio, defendendo justamente a maior proximidade do
} 
língua portuguesa no latim manter-se-á ao longo dos séculos e com poucas variações como a principal teoria sobre a origem desta língua.

\section{Outras teorias sobre a origem do português}

Apesar da forte implantação da teoria da filiação latina, outras teorias alimentaram o debate sobre a origem das línguas hispânicas, ainda que com muito menor expressão em Portugal. Por um lado, teve grande vigência no Renascimento europeu a teoria que postulava para as línguas europeias uma origem hebraica, e portanto, divina, por ser o hebraico considerado a língua divina e adâmica, a língua de Deus e do primeiro homem. A reflexão sobre qual teria sido a língua mais antiga da humanidade, presente nos clássicos greco-latinos, ausenta-se em grande medida nas obras renascentistas, assim como na patrística medieval, porque se assume literalmente a mensagem bíblica, considerando o hebraico a única língua existente até ao episódio babélico. A comunhão linguística da humanidade seria, pois, mais um dos presentes do paraíso, enquanto que a fragmentação e diversidade linguística eram entendidas como um castigo provocado pela soberba do homem, interpretando literalmente o episódio babélico. No entanto, acredita-se que, após a poligénese de línguas gerada na torre, o hebraico se teria mantido transfigurado, em maior ou menor medida, em todas as línguas, transmitindo-lhes as virtudes da língua original. Assim surgem diferentes teorias na Europa renascentista que filiam várias línguas europeias no hebraico (cf. Eco, I994). A mais conhecida é a de autoria de Gorópio Becano, quem defendeu veementemente tal origem para a língua neerlandesa, considerando os habitantes de Antuérpia como descendentes diretos da saga de Jafet (um dos filhos de Noé), que, por não estarem presentes na torre, teriam escapado à confusio linguarum. A tese flamenga teve curso até ao século xIx e mostra a importância desta teoria no norte da Europa, especialmente para justificar o tronco linguístico gótico (cf. ibidem).

Mas também no âmbito hispânico, e apesar do peso da assumida origem nobilitadora latina, teve alguma presença esta teoria, que se vinculava a uma genealogia mítica fundacional da nacionalidade: a que fazia dos portugueses e dos hispanos descendentes de Túbal, filho de Jafet e neto de Noé ${ }^{\text {. }}$

português primitivo ao latim: "Pelo que se póde affirmar com verdade q não era outra cousa esta maneira de falar senão hũ latim corrupto." (Gândavo, [I574] I981: 47).

${ }^{8}$ Por exemplo, o primeiro gramático português, Fernão de Oliveira, aceita sem discussão esta genealogia fundacional (cf. Oliveira, [I536] 2000: 84). 
Em Portugal é digna de menção a tentativa de explicação racional do mito da fragmentação linguística oferecida por Barros no seu Diálogo em Louvor da nossa Linguagem, argumentando que na torre não se criaram ex nihilo 72 línguas com significantes novos, isto é, com palavras novas. Pelo contrário, os significantes do hebraico ter-se-iam mantido, mas produzindo-se uma alteração dos seus significados, de forma que cada grupo humano dos 72 em que ficou fragmentada a humanidade entenderia por um mesmo significante um significado diferente, curiosa interpretação que lembra ao invés o episódio de Pentecostes no Novo Testamento (cf. Buescu, I984: 253-258). Estes significantes ter-se-iam transmitido por todas as línguas, de forma que todas elas, também o português, segundo o humanista, conservariam parte da língua divina, apesar da corrupção provocada pela passagem do tempo:

Quéro dizer que, quando Deos, naquéla soberba óbra, confundiu a linguágem, nam foi inventárem-se em um instante setenta e um vocábulos diferentes em vóz, que todos sinificássem ésta cousa, pédra: mas confundiu o intendimento a todos pera por este nome, hómem, uns entenderem pédra, outros as diferentes cousas que se, naquela edificaçám, tratávam. E este termo, confusám, nenhũa outra cousa quér / dizer senám tomár ũa cousa por outra. E assi ficaram todos com toda a linguágem em vocábulos, e com párte dos sinificados próprios. (Barros, [1540] 1971: 395-396)

Todas as línguas do mundo teriam, assim, a sua porção de língua divina:

Donde pódes entender que a linguágem primeira de Adám [h]oje está no mundo: em ésta naçám dez vocábulos, nest’outra vinte, e assi está repartida, que todos â têm em vóz, mas nam em um só sinificado. (Barros, [1540] I97I: 396)

A interpretação de Barros da fragmentação de Babel ecoa em autores posteriores, como em Severim de Faria, que recolhe a interpretação barrosiana (Severim de Faria, [1624] I999: 72-73) se bem que no autor barroco observemos já um distanciamento perante a língua hebreia, que perde o seu primado de antiguidade e de sacralidade como possível origem da língua portuguesa: "Por onde segundo a melhor, e mais verdadeira opinião, nem por primeira antiguidade, nem por incorrupção do idioma, pode nenhũa língua ser tida por melhor que a outra." (Severim de Faria, [I624] I999: 73).

Entretanto, vai abrindo caminho na Europa a hipótese poligenética, que afirmava a diversidade linguística desde o início dos tempos, não a considerando já como castigo mas como dom outorgado por Deus ou pela natureza (Eco, I991: 83). Assim, acredita-se que o lugar, o clima, a raça, dão origem a línguas 
diferentes, conformando-lhes um génio próprio e diferenciado. Justamente em virtude desse novo cenário que valoriza a diversidade, e no contexto cultural de construção ou enfatização das identidades nacionais, erigidas sobre os pilares do popular e do castiço, em suma, no âmbito cultural romântico de busca das origens populares da cultura nacional, é quando encontramos novas teorias folcloristas sobre a origem de línguas, que reivindicam para elas um génio linguístico próprio. Entre elas, merece especial atenção a hipótese celta e celto-cita, que defendia uma origem cita para todo o tronco celta, e que acaba remontando de novo à saga de Jafet (Eco, I99I: 92). Com bastante repercussão na Europa, no âmbito hispânico também tem uma certa expressão, sobretudo no oeste da Península. Assim, encontrará espaço no Portugal da primeira metade do século XIX a teoria de que o português remontaria não já ao latim mas ao celta, língua de presença pré-romana na Península. Os seus defensores consideram que a língua de um invasor (o latim dos romanos) não teria podido chegar a sufocar nunca o génio linguístico, bem diferente, do povo submetido. Assim, o português descenderia do celta pré-romano, tendo sido influenciado pelo latim apenas como superstrato. Para demonstrá-lo, os seus defensores procuram destacar as divergências linguísticas com o latim, sobretudo no âmbito morfossintático, atribuindo-as a um génio linguístico bem diferente do latino, numa atitude inversa à dos humanistas renascentistas, que procuravam as semelhanças para defender a origem nobilitadora latina. Na Itália havia um precedente bastante anterior para estas teorias, com um Giambullari que procurara no etrusco as raízes do toscano, defendendo, por sua vez, uma procedência do etrusco no arameu. Giambullari negara, na sequência desta teoria, a origem latina do toscano (cf. Marazzini, I999: 68-70).

A teoria celta não parece ter tido, no entanto, um grande curso na península, se exceptuarmos o seu âmbito cultural norocidental. Isto é devido, sem dúvida, a que existia uma tradição linguística consolidada, que procedia do Renascimento, que defendia a vigência de outra língua pré-romana, o basco, como língua geral da península à chegada dos romanos e na qual alguns viram também a matriz do castelhano. Esta teoria contava, aliás, com a vantagem da conservação dessa língua em parte do território, o que não acontecia com o celta na península, e com o facto de que a sua grande distância estrutural com relação ao latim impedia vinculá-la à língua mãe 9 . O debate sobre as

\footnotetext{
9 Considera-se que o basco é uma das 72 línguas surgidas após a confusão babélica que se converteram em matrizes das outras e teria vindo à península com Túbal. Flavio Josefo, que viveu entre 37 e roo d. C., na sua obra Antigüedades Judaicas, enumera os filhos de Jafet, entre
} 
línguas pré-romanas em Espanha tinha ganho protagonismo entre os intelectuais espanhóis dos séculos Xvi e xviI, convertendo-se em tema de referência obrigatória para os que se referiam às origens do castelhano ${ }^{\text {Io }}$. Nesta linha de interpretação da génese das línguas hispânicas integra-se também a teoria do castelhano primitivo, já mencionada. Para o seu principal defensor, Gregorio López Madera, o basco e o castelhano, trazidos por Túbal à península, eram já falados quando esta foi invadida pelos romanos, e teria sido o povo do Lácio o que corrompera essas línguas originais com o seu latim. Gonzalo Correas secunda esta posição na sua obra Arte grande de la lengua castellana española, aduzindo que era necessário "discurrir al revés, qe la Española fue la madre, i la latina hija i jirón suyo" (Correas, [1626] I903: 296). Assistimos aqui, portanto, a uma tradição que procura reivindicar e consagrar a natureza não espúria das línguas hispanas.

No Renascimento português e ainda depois ecoa a discussão sobre a língua primitiva da península, mas haverá que esperar vários séculos para encontrar a defesa de uma teoria que filie o português num vernáculo primordial. É apenas no contexto oitocentista de recuperação do genuíno que irão surgir as reflexões que fazem remontar a língua portuguesa diretamente à língua pré-romana celta. É conhecido o texto de Francisco de São Luís, cardeal Saraiva, publicado em I837 e cujo título é elucidativo: Memoria em que se pretende mostrar, que a Lingua Portuguesa não he filha da Latina, nem esta foi em tempo algum a lingua vulgar dos Lusitanos. Servindo-se constantemente do conceito de génio das línguas, o autor considera que não é possível determinar a matriz

os quais cita Túbal como fundador dos iberos. Esta ideia passa à obra de São Jerónimo e São Isidoro, e apoiada pela sua autoridade, e favorecida pela conexão etimológica com o rio Ebro, converte-se em dogma na Idade Média. Annio de Viterbo publica em finais do século XV textos em que especifica uma genealogia que começa com Túbal e que contém 27 nomes de reis de toda a península, constituindo-se em fonte para outros. Esta tradição apologista do basco conduz a Larramendi já no século xix (cf. Etxebarría, I999). Ainda que muitos contestassem que o basco tivesse sido a língua pré-romana comum a toda a península, a genealogia mítica que remonta a Túbal é geralmente aceite pelos autores da época.

1o Martín de Viciana, López de Madera ou os bascos Martínez de Zaldibia, Esteban de Garibay, Andrés de Poza ou Baltasar de Echave defendem, no séc. xvi ou princípios do xviı, a teoria da origem basca (cf. Etxebarría, I999). Outros autores da época como Valdés, Ambrosio Morales, Alejo Venegas ou Aldrete posicionam-se sobre o tema negando-a (Bahner I966: 36-38). A posição dos intelectuais portugueses em relação à língua basca é comummente negativa, como se aprecia no Diálogo em louvor barrosiano, ou nas seguintes palavras de Severim de Faria, extraídas de novo do seu "Discurso Segundo", em Discursos Vários Políticos: "E o mesmo se pode dizer aos Biscainhos, que afirmam ser o seu vasconço daquele tempo [de Nembrot], sendo tal que se não pode escrever" (Severim de Faria, [1624] I999: 73). 
da língua portuguesa a partir do estudo da origem do seu léxico, pois este procede de várias línguas, como a grega, fenícia, árabe ou orientais. O génio próprio da língua não há que buscá-lo nos vocábulos, mas deve ser julgado "pela sua estructura e construção; pela ordem e ligação com que ellas [as línguas] dispõem os seus vocabulos [...]; pelas differentes fórmas grammaticaes, com que modificão os mesmos vocabulos; e pelo emprego e lugar, que lhes dão no discurso" (São Luís, I837: 20). É na morfossintaxe que radica a índole e carácter dos idiomas, e que reflete o seu modo de pensar (ibidem). Assim, o autor compara em vários aspectos gramaticais ambas as línguas, latim e português: sistema casual, flexão de advérbios e comparativos do latim, diferenças na morfologia e sintaxe dos verbos, infinitivo flexionado e presença do artigo em português, sem deixar de referir, já no âmbito fraseológico, "adagios, anexins e rifões" que, segundo ele, nem procedem do latim nem se podem traduzir nessa língua. Recordemos que também Leão e Severim de Faria tinham mencionado, séculos antes, as expressões idiomáticas do português como sinal inequívoco de vernaculidade.

Outra parte da obra de São Luís está destinada a demonstrar que nem todo o léxico português ao qual se lhe supõe origem latina é realmente tal, e para isso o autor rejeita etimologias latinas flagrantes (amo, baba, boca, mimo, etc.) argumentando que os seus sons simples labiais sem dúvida surgiram espontaneamente da boca dos primeiros lusitanos. Igualmente considera vernáculas as interjeições e as onomatopeias, mas um conceito amplo delas leva-o a incluir nesse conjunto formas como assobio, bochechudo, gargalhada, murmúrio, trovão, chocalho, entre outras. São Luís procura supostas raízes originais vernáculas, das quais procederiam formas consideradas latinas tradicionalmente (como dum/dom, donde teriam surgido doar, donativo, e também donzel, dono, donoso, dama, etc.). Em definitivo, o autor chega a defender que os latinismos do português são tardios (dos séculos xv e xvi) e que apenas nos primeiros textos escritos em português é que se pode avaliar fielmente a presença do latim na conformação original do idioma.

Mais do que propriamente uma origem celta, São Luís parece querer defender uma origem pré-romana do português. Ele nem parece ter estudado detidamente o celta, nem sequer menciona autoridades sobre essa língua, que já havia na época. O propósito da sua obra encontraria sentido no intuito de defender a antiguidade e a vernaculidade da língua própria, considerando a sua origem no entroncamento pré-romano das línguas europeias. Contudo, esses esforços não puderam com a consolidada teoria tradicional da filiação latina, e a contundente contestação a esta teoria genolinguística por parte de 
intelectuais portugueses coevos, especialmente Alexandre Herculano, sem dúvida truncou a sua circulação, como expôs Gonçalves (200I).

\section{Em jeito de conclusão}

Concluímos este breve percurso sobre as principais teorias sobre a origem da língua portuguesa destacando a importância que elas têm para o discurso fundacional de qualquer nação. No caso português tiveram curso três teorias: a que postulava que o português era uma corrupção do latim; a que defendia a sua porção de divindade, enraizando-o no hebraico original; e mais recentemente, no caso português, apenas no século XIx, a que quis defender uma origem não espúria da língua nacional, que enfatizasse a autenticidade da origem. Em relação às duas teorias genolinguísticas primeiramente referidas, a latina e a hebraica, importa referir que ambas são teorias integradoras, em que se constrói uma identidade linguística como resultado da integração do povo português num espaço cultural comum, seja ele a latinitas ou a cristandade (sendo o hebraico a língua fundacional desta última). Já no séc. XIX, em Portugal, como em toda a Europa, as línguas sagradas do Renascimento tinham perdido a sua primazia. Como afirma Anderson ${ }^{\text {II }}$, elas colocaram-se ontologicamente ao nível dos plebeus vernáculos, num movimento que complementou a sua derrogação pelo capitalismo (Anderson, I991: 70). A expansão burocrática e a ascensão de uma burguesia comercial e industrial é relacionada por Anderson com o conceito de print-capitalism vernacular. Assim, afirma este autor que a burguesia foi a primeira classe em conseguir solidariedades sobre uma base essencialmente imaginada (Anderson, I991: 77). Em coerência com este princípio, podíamos postular que as bases culturais sobre as quais se assentou a valorização do próprio idioma português desde o século xvı, basicamente uma identidade cultural clara no paradigma da latinitas, não servia já à burguesia letrada portuguesa, ou a parte dela pelo menos, que foi assim procurar as raízes de sua identidade em povos considerados mais vernáculos que os mesmos latinos.

\footnotetext{
II Em finais do século xvıı realizam-se já investigações pioneiras sobre o sânscrito, proporcionando a ideia de que a civilização índia era mais antiga que a grega e a judaica. $\mathrm{O}$ estudo dos hieroglíficos egípcios e sobre o semítico acabam com a ideia de que o hebraico era a única língua de proveniência divina (Anderson, I991: 70).
} 


\section{Bibliografia citada}

\section{Fontes}

Aldrete, Bernardo J. de. [1606] I972-I975. Del origen y principio de la lengua castellana ò romance que oi se usa em España. (Ideas linguísticas de Aldrete). Edição fac-símile e estudo de Lidio Nieto Jiménez, 2 vols. Madrid: CSIC.

Barros, João de. [1540] I97I. Gramática da Língua Portuguesa. (Cartinha, Gramática, Diálogo em louvor da nossa linguagem e Diálogo da viciosa vergonha). Reprodução facsmilada, leitura, introdução e anotações por Maria Leonor Carvalhão Buescu. Lisboa: Faculdade de Letras.

Correas, Gonzalo. [I626] I903. Arte grande de la lengua castellana, compuesto em 1626 por el Maestro Gonzalo Correas. [Madrid]: s. n.

Faria, Manuel Severim de. [I624] I999. Discursos Vários Políticos. Lisboa: Imprensa Nacional-Casa da Moeda.

Gândavo, Pero Magalhães de. [1574] I98I. Regras que ensinam a maneira de escrever e ortografia da língua portuguesa. Com um diálogo que adiante se segue em defensão da mesma língua. Edição fac-similada da I a edição. Lisboa: Biblioteca Nacional.

Leão, Duarte Nunes de. [1606] I983. Ortografia e origem da língua portuguesa. Introdução, notas e leitura de Maria Leonor Carvalhão Buescu. Lisboa: Imprensa Nacional-Casa da Moeda.

Nebrija, Elio Antonio de. [I492] I992. Gramática castellana. Introdução e notas de M. A. Esparza e R. Sarmiento. Madrid: Fundación Antonio de Nebrija.

Oliveira, Fernão de. [1536] 2000. Gramática da Linguagem Portuguesa. Edição crítica, semidiplomática e anastática de Amadeu Torres e Carlos Assunção. Lisboa: Academia das Ciências de Lisboa.

São Luís, Francisco. I837. Memoria em que se pretende mostrar que a lingua portugueza não é filha da latina, nem esta foi em tempo algum a lingua vulgar dos lusitanos. Inserta no tomo XII, parte I, das "Memorias da Academia Real das Ciências".

Valdés, Juan de. I985 [I535]. Diálogo de la lengua. Edição de Juan M. Lope Blanch. Madrid: Castalia.

\section{Estudos}

Anderson, Benedict. [I983] I99I. Imagined Communities. Reflections on the Origin and Spread of Nationalism. London-New York: Verso.

Bahner, Werner. I966. La linguística española del Siglo de Oro. Aportaciones a la conciencia lingüística en la España de los siglos XVI y XVII. Madrid: Ciencia Nueva.

Binotti, Lucia. I995. La teoría del "Castellano Primitivo". Nacionalismo y reflexión lingüística en el Renacimiento español. Münster: Nodus Publikationem.

Buescu, Maria Leonor Carvalhão. I984. Babel ou a ruptura do signo. A gramática e os gramáticos portugueses do século XVI. [Lisboa]: Imprensa Nacional-Casa da Moeda. 
Eco, Umberto. I994. La búsqueda de la lengua perfecta. Barcelona: Crítica.

Etxebarría Aróstegui, Maitena. I999. La tradición apologista y su incidencia en la configuración de la historiografía lingüística vasca. Em Fernández Rodríguez, Mauro \& García Gondar, Francisco \& Vázquez Veiga, Nancy (eds.) Actas del I Congreso Internacional de la Sociedad Española de Historiografía lingüística (A Coruña, I8-2i de febrero de I997). Madrid: Arco Libros: 257-270.

Gonçalves, Maria Filomena. 200I. A Celtomania - Um tópico da Linguística Romântica. Diana, Revista do Departamento de Linguística e Literaturas da Universidade de Évora (I-2): 4I-58.

Hernando García-Cervigón, Alberto \& Sánchez Rodríguez, Cristina. 2000. Sobre el origen del romance y la teoría de la "corruptio linguae". Didáctica (Lengua Y Literatura) (12): I67-I82.

Marazzini, Claudio. I999. Da Dante alla Lingua Selvaggia. Sette secoli di dibattiti sullitaliano. Roma: Carocci. 